\title{
Intrinsic Value of the Natural Environment: An Ethical Roadmap to Protect the Environment
}

\author{
Nader Ghotbi \\ Ritsumeikan Asia Pacific University
}

\begin{abstract}
The environment in the sense of all the ecosystems on Earth, has been polluted, harmed, and put at risk of degradation to some extent. Nevertheless, the mainstream ethical philosophies have found it difficult to assign an intrinsic value to the environment itself, and most environmental ethics is based on an "enlightened" anthropocentrism which values environmental protection for the sake of other humans including the future generations. Philosophically speaking, the concept of moral obligations towards generations, who have not been born yet, can be challenged. This vicious circle is a fundamental issue for "environmental ethics." The current paper is an attempt to help correct this broken cycle of arguments using three lines of argument: (1) The harmful impact of human activity on the environment does not benefit all humans; the question is not over the selfishness and short-sightedness of humankind regarding the environment as much as it is regarding "environmental" justice among humans. The pursuit of self-interest and wealth by some humans, but not all, should not lead philosophers to ignore the insufficiencies of our economic and capitalist systems in the delineation of morally correct human-environment interaction. The right to a livable environment is a universal human right and morality has to support it. (2) The moral obligation of humankind toward the environment is similar to any situation where a party, such as a child, does not have the ability to protect itself or defend its rights; this is the principle of "due care." Humans have the knowledge to understand the complexity of ecosystem interrelationships and the harm which industrial activity has caused. Therefore they have a moral obligation to exercise due care to prevent it from being harmed irreversibly. (3) The third argument is concerned with human morality and the spirituality of the environment. It can be argued that the natural instinct of the love of the environment, biophilia, is not a cause but a symptom of the grand spiritual value in the environment, even though this spiritual value may not be confined to humans, but be accrued to all life forms that have and/or show a genuine interest in the environment.
\end{abstract}

Keywords: environmental ethics, instrumental vs. intrinsic value, natural environment

\section{Introduction}

Many of the environmental catastrophes that have happened before and others that are happening in our time have been caused or intensified by human activity. These catastrophes have caused a wide variety of harmful medical, social, economic, and political consequences that are commonly regarded as more important than the ecological consequence for the ecosystems and the environment itself. All too commonly, we talk of

Nader Ghotbi, M.D., Ph.D., professor of bioethics and health science, College \& Graduate School of Asia Pacific Studies, Ritsumeikan Asia Pacific University, Japan; main research field: Environmental Ethics, Public Health Ethics, and Ethics of Japanese Society. Email: nader@apu.ac.jp. 
the environment as a mere resource for mankind that must be overcome and used and then its unwanted components are safely disposed out of human life. This gives the environment an "instrumental value" and doing so automatically puts it second to all other values; the environment can hardly be protected without arguments for its "intrinsic value" lifting it to a higher ethical platform (Brennan 2009). Having intrinsic value would imply that the environment is an "end" in itself, not just a "means" to an end, which is commonly the position of mankind.

A few concepts have been put forward as intrinsic values of the environment such as beauty, but mainstream ethical philosophies have failed to support a strong intrinsic value for the natural environment. Some natural scientists have become so disappointed with this general attitude of the mainstream ethics towards the environment that they have stated environmental problems should be looked upon from a scientific perspective, not an ethical one, because ethics by its dominant stance of "mankind superiority" cannot help solve any "environmental" problem (Tarlock 1996). I believe that such a statement by itself is evidence to the need for a reappraisal of our ethical valuation systems and ways of thinking about moral issues in the 21st century; and this paper represents my attempt to do that.

A root cause of the issue that is raised here could be the increasing gap between the ethical and scientific understanding of the world we live in. While science has progressed with an exponential speed and allowed our scientists to become more and more familiar with the complex role of the ecosystems as a universal web of life support systems, mainstream ethics is still based on a traditional philosophical worldview that assigns the most superior position to mankind.

Scientists have found evidence that shows humankind is a recent species in the approximately 3.5 billion-year-old life in evolution on this planet, and we, the Homo sapiens, are only one species of humans that lives for generations before they mostly become extinct. Homo sapiens is thus a very young species with a highly risky future on the geological scale; the danger of extinction from a mutating virus or a number of other global disasters threatens us more than many other species. Apparently, a distorted "mankind dominant" worldview may have played a role in problems resulting from ignorance, arrogance, greed, and overconsumption, which are not our highest moral characteristics.

Moreover, the theory of evolution has explained how the "natural environment" is selected for the evolving appearance and abilities of modern humans from their ancestors in the last two million years, emphasizing the fact that Homo sapiens is the result of millions of years of adaptation to the environment. Nevertheless, Homo sapiens with their wisdom is able to "manage" the surrounding environment beyond the limits of "adaptation," and the human impact on the environment becomes the source of problems such as "global warming" and "climate change."

Environmental management requires an ethical valuation system that is different from the past. How could the humans live in ancient time dream of an age when their chemical products would damage the protective ozone layer around the earth to endanger life for all its inhabitants? Humankind should no longer ignore the complex web of interactions and the delicate system of life sustaining components in the environment.

Here, I am going to use three arguments to support the fundamental value of environment, especially its "intrinsic" value, and lift the significance of environmental ethics to the same level of other fields of ethics. These three arguments are made on a basic premise that bioethics is and needs to be an interdisciplinary way of thinking; I shall use our knowledge of economics and science as well as philosophy and religions for reasoning to support my arguments. Science means "knowledge" as the original Latin word implies ("to know") and the 
knowledge of science may be specified as "to know by proof," so that the premises in building philosophical arguments may be both sound and valid.

The environment of our planet, including its unique ecosystems, has been polluted, harmed, and degraded to some extent. Nevertheless, mainstream ethical philosophies have difficulty in assigning an "intrinsic value" to the environment, and therefore environmental ethics is mostly built on "enlightened" anthropocentrism. That implies environmental protection is valued for the sake of humans including the future generations (Lehman 1995), but not for the sake of the environment itself. Complicating this is the philosophical question whether one can defend moral obligations to generations who have not been born yet. As an example, a child cannot complain to his mother that if she took more calcium, he would be taller; the mother may respond: Yes, my child would be taller but it would not be you! In a similar way, if environmental policies result in pollution and depletion of natural resources, future generations cannot complain because "they" would not have existed under a different set of policies!

This vicious circle leaves philosophers with a worldview that regards the environment as an instrument for the use of humankind as he sees fit for a reasonably foreseeable future, and nothing more. As long as an intrinsic value for the environment has not been established, our mainstream ethics may see it next to human needs and desire for happiness (Takahashi 2009). In a pervasive culture of consumerism, our happiness comes at a considerable cost to the environment. The current paper is an attempt to help correct this broken cycle of arguments.

\section{The Three Arguments}

I suggest the three following lines of arguments:

The damages to the environment resulting from human activity do not benefit all humans. In other words, it is not a "man versus the environment" conflict as much as a conflict between men. The concept of "environmental justice" requires one to protect the environment because it is a resource for all men. Not all humans live in a just world; distributive justice implies that humans would benefit equally from inevitable harm to the environment when it is used by human activity. However, the world's socioeconomic systems follow a completely different picture; industrial countries for instance have put a lot more pressure on environmental resources while they are a lot better equipped to protect themselves from the ensuing pollution and harm. Within each country too, the widening gap between the rich and the poor demonstrates how economic development brings more of prosperity and happiness to the wealthier people but more of environmental pollution and harm to others. The pursuit of self-interest and wealth by some humans, but not all, should not be confused with a general conflict between the man and the environment, and ethical philosophers must consider the insufficiencies of capitalist economic systems when defining morally sound human-environment interactions. As long as the environment is valued as a "means" only, but not an "end" in itself, it may be used for the prosperity of industrial corporations who may freely exercise their autonomy on how they want to use the environment, while the rights of all the living, including humans, to live in a clean, healthy, and livable environment, hence the "intrinsic value" of the environment cannot be protected. If we regard the environment as having intrinsic value, or the right to a livable environment, justice will require us to assure every human his/her access to the optimum, not just the minimum needed; this is how the loophole that exists in traditional worldviews can be closed. The intrinsic value of the environment could be in its beauty, freshness, cleanliness, and other characteristics that mankind appreciates as the attributes of a livable environment. The "right to a 
livable environment" (Blackstone 1975) in this view is a universal human right, and morality has to support it. It has as much intrinsic value as the right of humans to autonomy and dignity, and the society has a duty to protect it for all individuals, disregarding their material wealth and socioeconomic status.

The concept of human stewardship over the nature is as old as our oldest religions. Secular philosophies have stated a similar concept in different forms but the basic premise is the same. The moral obligation of humans toward the environment is similar to any situation where a party, such as a child, does not have the ability to protect itself or defend its rights; this is called the principle of "due care." We do not "own" the environment, but may act as its "guardian." The main difference is that for a child, we need to do things that show we care, but for the environment, we need simply not to destroy, destruct, or damage it irreversibly. If a child has a "positive right" to be cared for, the natural environment will have a "negative right" not to be harmed further than its capacity to stay in balance. It is true that the humankind has an amazing power of observation to discover and invent but the invention and industrial manufacture of "things" have led to the build-up of a large amount of pollution with exotic material that harms the natural environment and its vital components. Non-biodegradable pollutants and chlorofluorocarbons (CFC) are good examples.

Scientists may use a different way to imply the principle of "human stewardship" or "due care" over the environment; humans have the "knowledge" to understand the complexity of ecosystem interrelationships and the harm which industrial activity has caused. Therefore, they have a moral obligation not to harm it irreversibly. What all these various perspectives share is the understanding that to preserve the natural environment is a value by itself. There is also another intrinsic value that we can assign to the environment without defining it specifically; the (genetic) "information" within each species (gene pool and genetic variation) has both an intrinsic and instrumental value for the species and their populations. This is about the "survival" of all species, including humankind. This intrinsic value is not limited to the information within unique genetic forms but also includes the information within their living habitats that together make the complex web of interrelationships that support all life in general.

Humans "care" for the environment and appreciate what it provides in material and non-material forms (beauty, as well as information). Such "care" contradicts the ignorance of an ethical directive by requiring the humankind to "appreciate the (intrinsic) value of the environment." People may "care" about the environment following religious or spiritual conventions, or because of scientific revelations. In the end, everybody should care about the environment for what it means to "life"" and "the living," including mankind.

The third argument revolves around the spiritual relationship of mankind to the environment as a "moral resource" in itself. Science confirms the fact that humans for their biological livelihood depend on ecosystems (Tarlock 1996), and "deep ecologists" go as far as to claim that the natural environment is the ultimate distributor of life and whatever comes with it (Ball 2003). Biophilia is a hypothesis that refers to an innate love towards the nature supposedly out of the need to live within nature. This love and need could have resulted from the "instrumental" use of the environment but the "emotional" tendency and inclination towards nature may not be based on "instrumental" use; it is rather like a spiritual connection. As such, the human instinct for the love of the environment, or biophilia, is not a cause but a symptom of the grand spiritual value in the environment. This spiritual value is not confined to humans but to all life forms that have and/or show a genuine interest in the environment. Almost all life forms show their interest in the natural environment and the habitats which support their life. Such references to the role of the natural environment in the development and the very existence of life confirm our intrinsic love of nature and support the value of the environment as a 
moral resource; the environment may be appreciated as a spiritual resource to all life as well as a moral resource to all humans (Partridge 1984).

\section{Conclusions}

Thus far, I have presented three arguments to support the intrinsic value of the environment. We may need to further analyze the nature of the intrinsic value itself, and comprehend how it could be promoted as a moral value in the society; is it beauty, love, or a philosophical value related to the environment's role in sustaining all life, including human life? These questions could be further examined in detail through other studies.

Having presented the arguments, I must confess that a significant issue that cannot be resolved by just "ethics" is the basic reality that the environment has significant "instrumental" value and therefore it may be "overused" and treated only as "resource." The challenge of our generation is how to balance the use of the environment for our various needs, with respecting it for its other intrinsic values, as well as protecting it for the future. Most experts would agree that as long as the human-caused damage to the environment is not irreversible and ecosystems can absorb the percussions of these damages, we have not done "ethically" wrong.

However, a point of concern is the commonly associated "uncertainty" and the risk of irreversibility of some of the environmental harm caused by "human usage." The "precautionary principle" is the main method to deal with such a risk, though in practice it may be too difficult to follow (Dobson 1995).

Finally, I would like to emphasize that ethical issues have a more significant relationship with environmental problems than commonly recognized. For instance, ethical decision-making in reproductive health and family planning may be assisted with an understanding of the problems associated with human overpopulation, such as pollution and poverty. There are also historical examples of human communities being totally dispersed and/or eliminated because of the lack of a proper understanding on how to balance their relationship with their natural habitat, such as the Maya and Mesopotamia civilizations. A whole new discipline called "human ecology" studies the complex relationships between humans and natural ecosystems.

Some experts have already suggested that ethics had better be left out of discussions over environmental problems because it has failed in providing a balanced view that incorporates our current knowledge, supported by scientific evidence (Brown 1992). An alternative solution would be to upgrade our traditional self-centered ethics in the light of all knowledge we have gained with scientific methods. There is a lot more philosophy to look for in the study of human relations with the environment, and it would be too hasty to claim that we have reached a final verdict on our ethical obligations towards the environment. What I sincerely hope for is that the arguments presented in this paper, as well as similar appeals by the experts of environmental ethics and the scientific community, can be taken more seriously and it can lead to a wider discussion of the ethics of the environment.

\section{Works Cited}

Ball, Terence. "Deep Ecology." Environmental Encyclopedia. 2003. <http://www.encyclopedia.com/article-1G2-3404800400/ deep-ecology.html>.

Blackstone, William. Philosophy and Environmental Crisis. Athens: University of Georgia Press, 1975.

Brennan Andrew and Yeuk-Sze Lo. "Environmental Ethics.” The Stanford Encyclopedia of Philosophy. Edward N. Zalta, ed. 2011. $<$ http://plato.stanford.edu/archives/fall2011/entries/ethics-environmental/>. 
Brown, Donald. "After the Earth Summit: the Need to Integrate Environmental Ethics into Environmental Science and Law." Journal of Environmental Law and Policy 1.17 (1992). <http://ssrn.com/abstract=2304259>.

Dobson Andrew and Paul Lucardie. The Politics of Nature: Explorations in Green Political Theory. London and New York: Routledge, 1995.

Lehman, Glen. “A Legitimate Concern for Environmental Accounting.” Critical Perspectives on Accounting 6.5 (1995): $393-412$. Partridge, Ernest. "Nature as a Moral Resource.” Environmental ethics 6.2 (1984):101-30.

Takao Takahashi. "A Synthesis of Bioethics and Environmental Ethics Founded upon the Concept of Care: Toward a Japanese Approach to Bioethics." Taking Life and Death Seriously_Bioethics from Japan (Advances in Bioethics, Vol. 8), 2005. $19-45$.

Tarlock, Dan. “Environmental Law: Ethics or Science.” 7 Duke Environmental Law \& Policy Forum, 1996. 193-223. 